\title{
Lesson Study and Lesson Sharing: An Appealing Marriage
}

\author{
Mackenzie Hird', Richard Larson'1, Yuko Okubo², Kanji Uchino² \\ ${ }^{1}$ Engineering Systems Division, Massachusetts Institute of Technology, Cambridge, USA \\ ${ }^{2}$ Open Education Solutions, Fujitsu Laboratories of America, Sunnyvale, USA \\ Email: $\underline{\text { mhird@mit.edu }}$
}

Received 30 April 2014; revised 27 May 2014; accepted 8 June 2014

Copyright (C) 2014 by authors and Scientific Research Publishing Inc.

This work is licensed under the Creative Commons Attribution International License (CC BY). http://creativecommons.org/licenses/by/4.0/

c. (i) Open Access

\begin{abstract}
Lesson study and lesson sharing are two educational initiatives that, if merged, have the potential to revolutionize how teachers plan and deliver lessons. Lesson study is the joint production of lessons by a small team of teachers over the course of a few months. The resulting lesson plan is usually "on paper" and used only locally. Lesson sharing occurs on the Internet, providing contributing teachers with a mechanism for sharing their lessons with others. Typically a single teacher authors these shared lessons. We discuss the advantages and associated implementation barriers of each when viewed as separate activities, and then argue for their joint or merged implementation, describing how each would synergistically support the other. Not only would more vetted lessons be delivered to the Internet, but also the teacher teams participating in lesson creation would develop a much deeper understanding of pedagogy. We offer policy recommendations to support this new educational paradigm: A virtual marriage of lesson study and lesson sharing.
\end{abstract}

\section{Keywords}

Lesson Study, Lesson Sharing, Technology Enabled Education, Professional Development

\section{Education as a Craft Industry}

Today's dissatisfaction with elementary and secondary school education is not unique. The public's perception of the problem and required solutions seems, over decades, to be almost cyclical in nature. Our story here begins with American schools in the mid-to-late 19th century. The schools were under public pressure to move away from emphasis on rote learning and toward student-centered learning techniques. Many Americans had taken an interest in the ideas of German-born Johann Pestalozzi, who envisaged that schools should be "creating situations in which students learned from their own experiences, rather than from the authority of the textbook and 
the school teacher” (Rillero, 1993).

Notably, much recent pedagogical research supports such an approach. But in the 19th century such hands-on lessons were difficult for many teachers to implement effectively and, as such, early attempts at introducing Pestalozzian teaching failed until educators began concentrating on teacher training in the form of focused teacher professional development (PD). Edward Sheldon of the Oswego (New York) Primary Teachers' Training School operated the most notable Pestalozzian teacher-training program, where Lesson Plan development, pre-service internships, and numerous other hallmarks of effective teacher training were first introduced (Rillero, 1993). The graduates of this program spread across the country and had individual successes. But problems emerged when the techniques were attempted at scale, with the majority of teachers never having participated directly in the Oswego program and hence unprepared. Apparently, the Oswego graduates were not successful as trainers and had not been trained to train others. The many insufficiently trained teachers became overwhelmed, threw in the towel, and Pestalozzi's message was diluted and lost. Lesson Plans became scripts, exploratory lessons became lectures on what students should understand from experiments, and teachers moved back toward rote memorization. A key lesson here: Do not underestimate the value of teacher training.

The daily routines of teachers have remained roughly the same since these 19th-century efforts, even as new educational theories have come and gone over the decades. Teachers in isolation, working late into the night, produce homemade lessons to teach the next day (Figure 1). In essence, education remains a craft industry, with each classroom a "site of small scale industrial production often involving hand work and craft skills" ("Building Types Thesaurus”). However, over the last century most other service industries have been aided by technological advancements, allowing workers to become more productive (Larson, 2009; Larson, 2011). For instance, ATMs have removed the need for routine dispensing of money by bank tellers, allowing banks to focus more on addressing customer problems and selling other financial products. With the exception of many promising exploratory efforts, some of which we will discuss, in-class education remains relatively unchanged by technology.

We present two educational initiatives that show promise for revolutionizing particular aspects of the education system. The first, lesson study, can break the isolation of teachers via its collaborative lesson planning process. The second, lesson sharing (usually via the Internet), can move teachers away from an isolated craft industry environment by offering high-quality, vetted lessons so teachers can focus less on lesson planning and more on helping students individually. While each of these initiatives has shown promise, we believe their coimplementation could be a classic case of $1+1=3$, that is, synergism.

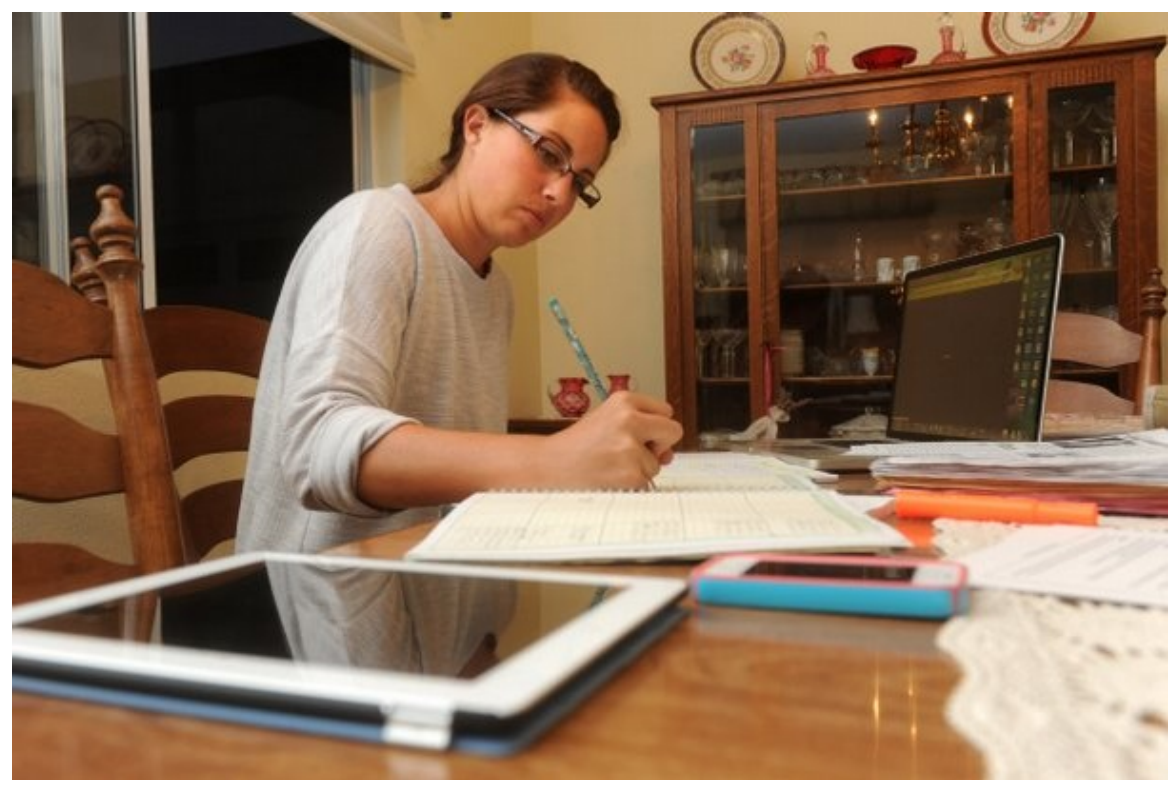

Figure 1. Petra Somar, a teacher at Sunset School in Oak View, CA, works on upcoming lesson plans at her home in Ventura. The 28-year-old begins her workday at 7:15 a.m. and often works until late evening.

http://www.vcstar.com/photos/galleries/2013/nov/10/teacher-salaries/69246/\#section header 


\section{Lesson-Sharing Services Fulfill a Demand}

Lesson sharing occurs when a teacher prepares her/his lesson for others to use and posts it on the Internet. In recent years, lesson-sharing services have grown exponentially. Demand for shared lessons is creating a large supply. Common standards make this possible.

Teachers in the United States are overwhelmed by teaching hours, both in class preparation and in front of the classroom. A recent OECD study found that US teachers rank second after Chile in terms of class time spent in front of students (Figure 2). For instance, despite Japanese schools teaching four extra weeks per year, Japanese primary school teachers only spend 707 hours per year teaching compared to the 1100 hours per year for their US counterparts (OECD, 2012). This difference is even greater at the middle-and high-school levels, where US teachers spend 1070 and 1050 hours respectively compared to 602 and 500 hours for Japanese teachers. Despite these large differences in instructional time, teachers in the two countries work comparable hours in total (1899 hours in Japan and between 1913 and 1998 hours in the United States, according to the OECD). Teachers in the United States are expected to grade student work, perform administrative work, and prepare high quality lessons, all within one hour for each hour they spend in front of the classroom. Japanese teachers have approximately three hours of preparatory time for each hour they spend actively teaching. While many US teachers compensate by working even longer hours, such a path is not sustainable and contributes to high teacher turnover rates (Ingersoll, 2001).

In a bid to help overwhelmed teachers move away from daily handmade lesson planning, some educators have begun to share their lessons online. While lesson sharing traditionally occurs within individual schools, the Internet allows teachers to post their lessons online so colleagues from around the globe can benefit. Today there are numerous lesson-sharing services. They typically consist of large databases of lesson plans, as well as accompanying materials or videos, organized by content and grade level. In this way, lesson-sharing services can be viewed as an attempt to "crowdsource" lesson planning and allow teachers to harness resources that have already been created elsewhere.

Lesson-sharing services now have wide followings; Figure 3 shows some samples of their logos.

TeachersPayTeachers.com, for instance, has more than 750,000 lessons that have been downloaded 13.7 million times (TeachersPayTeachers.com). One kindergarten teacher, Deanna Jump, has earnings from TeachersPayTeachers in excess on \$1,000,000. Total teacher earnings have exceeded \$30,000,000 (EdSurge, 2013). BetterLesson.com has more than 600,000 lessons, and in 2013 averaged greater than 300,000 visitors a month (BetterLesson.com). ShareMyLesson.com, a project of the American Federation of Teachers, has been one of the fastest growing of these services, with nearly 250,000 lessons contributed in its first year of operation (ShareMyLesson.com). Khan Academy has more than 3000 lectures created by Sal Khan and other experts; combined, they have been viewed more than 320 million times (KhanAcademy.com). MIT BLOSSOMS has more than 100 shared interactive lessons created by teachers and students in nine different countries. Although the online lesson-sharing space is diverse and each of these services utilizes a unique approach, all lesson-sharing services have two main goals: public posting of lesson plans and curation to help organize and identify the appropriate lesson for each teacher. To achieve these goals, lesson-sharing services either use experts or crowdsourcing, with and without money exchanged. Table 1 shows three different approaches to lesson sharing (including for the blended model we propose later in this paper).

Crowd-sourced lesson sharing is accomplished by enabling teachers to upload their lesson plans, to be shared online. BetterLesson, ShareMyLesson and TeachersPayTeachers are examples. Participating teachers are motivated either by altruism (BetterLesson and ShareMyLesson) or by possible monetary gain (TeachersPayTeachers). Crowdsourcing results in each of the sites having hundreds of thousands of lessons. However, such large numbers create problems for users. There is little information about lesson quality, and the numbers are so large that individual experts cannot curate the collections to identify high-quality lessons. Instead, these services often rely on user-teachers to rate each lesson individually; this happens after or, more likely, before they ever use them in their classrooms. With such unreliable ranking systems, teachers must spend time sorting through myriad online lessons for potential adaptation to their own specific needs, often leading to little or no time saved compared to the homemade craft alternative.

One teacher with whom we have worked remarked, “[T]he quality of lessons on these sites is so uneven. I can often write my own lesson plan in the time it takes to sort through what will work and what won't.” Thus, relying solely upon unvetted crowdsourcing for these lesson-sharing services leads to curation difficulties, forcing teachers to spend unneeded time. 


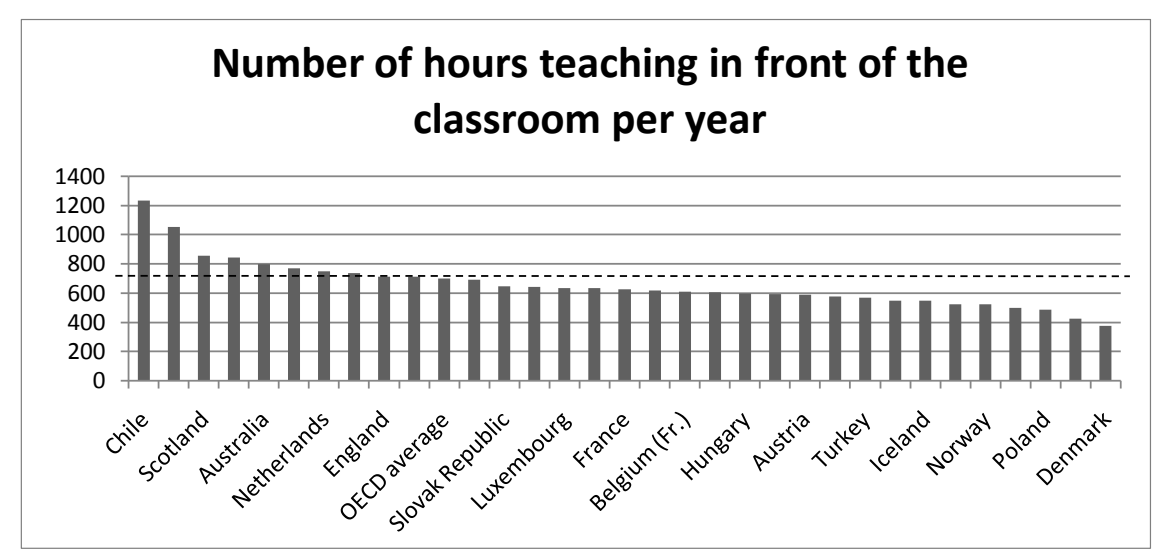

Figure 2. Time spent teaching in the classroom across OECD countries.

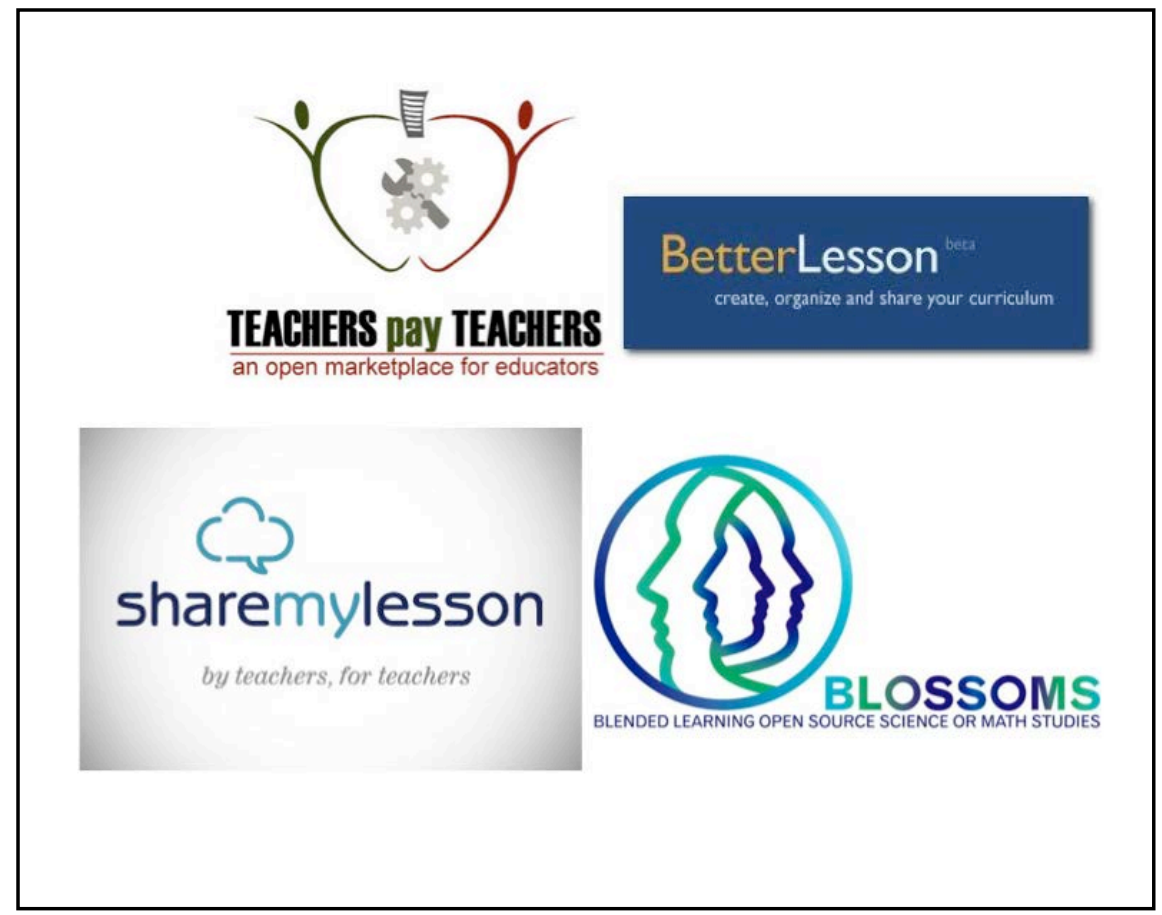

Figure 3. Logos of some of the popular lesson sharing services.

Table 1. Different approaches to lesson sharing.

\begin{tabular}{|c|c|c|c|c|}
\hline & \multicolumn{2}{|c|}{ Goal: Create high-quality lessons } & \multicolumn{2}{|c|}{$\begin{array}{l}\text { Goal: Curate the lessons for quality and } \\
\text { identify relevant lessons for particular subjects }\end{array}$} \\
\hline & Developer & Reward for developer & Method & Measure of quality \\
\hline $\begin{array}{l}\text { BetterLesson } \\
\text { ShareMyLesson } \\
\text { NSTA Learning Center }\end{array}$ & Individual teachers & No & Crowd sourcing by teachers & Ratings \\
\hline TeachersPayTeachers & Individual teachers & Yes & Crowd sourcing by teachers & Ratings and sales \\
\hline CPALMS & Individual teachers & No & Expert review & Criteria \\
\hline $\begin{array}{l}\text { Khan Academy } \\
\text { MIT BLOSSOMS }\end{array}$ & Experts & Yes & Expert review & Criteria \\
\hline $\begin{array}{l}\text { Proposed blended } \\
\text { model }\end{array}$ & Lesson Study Teams & No & Lesson Study & $\begin{array}{l}\text { Seal of Approval from Lesson } \\
\text { Study }\end{array}$ \\
\hline
\end{tabular}


A notable vetting exception is CPALMS, an OER curation service operated by Florida State University. Anyone can submit OER educational content to CPALMS for possible posting on the CPALMS and Florida Department of Education (FLDOE) websites. Each submission is sent to a team of both teaching experts and content experts, who accept only the best lessons for CPALMS. The curation team also denotes the set of Florida state education standards met by offering each lesson. In this way, CPALMS provides a most valuable vetting/ curation service. Any lesson posted there has, in essence, the equivalent of a "Good Housekeeping Seal of Approval."

Expert-led sites work only with quality content. Khan Academy, for example, identifies experts in a field and hosts the videos they create. MIT BLOSSOMS, a project lead by one of the authors since 2007, identifies interested and expert educators and then works with them through a rigorous collaborative design process to ensure high-quality interactive learning videos. Expert-led sites are thus pre-engaged in curation for quality. However, such models may break down when brought to a large scale, as it is unlikely that any expert-led creation entity can match the hundreds of thousands of lessons supplied through crowdsourcing.

\section{Lesson Study Supports Quality Lesson Plan Development}

\subsection{The Lesson Study Process}

In an attempt to move away from isolated solo lesson creation, Lesson Study (derived from a Japanese phrase [1]) is the practice of collaborative lesson design and planning by a small group of teachers, typically four or five. This practice has been developed and refined since the late 19th century in Japan, where educators were also motivated by Pestalozzi's ideas for active learning. Observing the American experience and its concomitant difficulties, Japanese educators in the late 1800s brought in American educators familiar with Pestalozzi's ideas and then focused heavily on teacher education, also known as professional development (Makinae, 2010). Where many US teachers were overwhelmed by the difficulty of teaching Pestalozzian exploratory lessons, Japanese teachers took teacher preparation one step further and began to work together and exchange ideas (Arani, Fukaya, \& Lassegard, 2010). This led to successful Pestalozzi-inspired lessons in the classroom, and the informal practice spread across Japan and evolved to its current form (Figure 4).

Notably, Lesson Study is now viewed as a specific example of the ongoing Japanese devotion to the Plan-DoCheck-Act (PDCA) decision making process pioneered by W. Edwards Deming, which is based on the Shewhart Cycle (named for Walter A. Shewhart, Deming's collaborator from Bell Telephone Laboratories) (Pavey, 2012). Deming spent a great deal of time in Japan from 1950 on, leading the country to develop world-class excellence in manufacturing and business. The Deming Prize is considered Japan's most prestigious prize in total

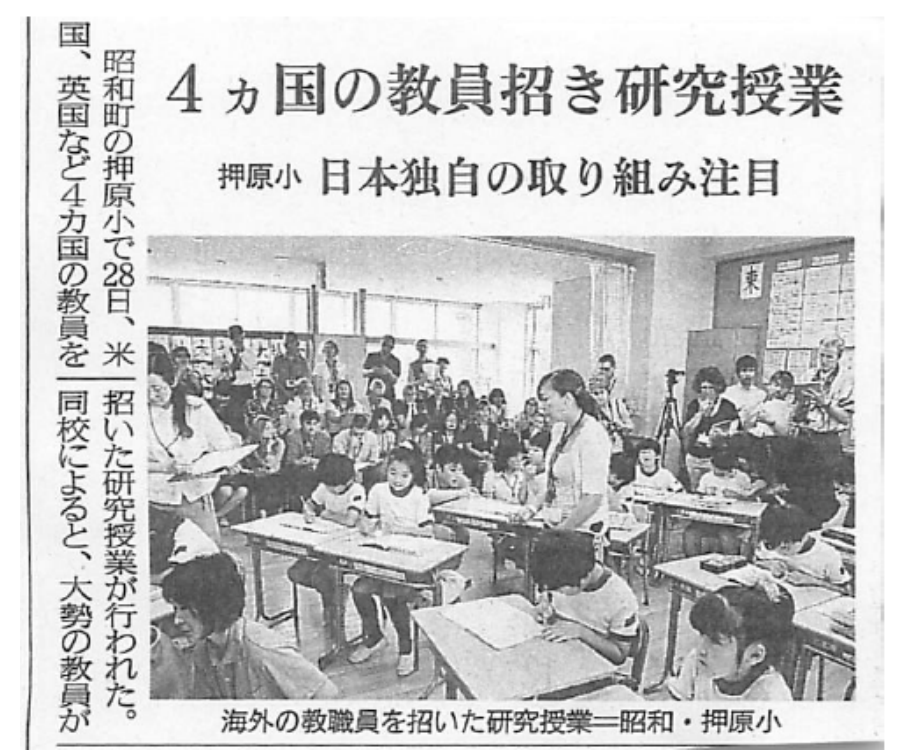

Figure 4. An example of a lesson study class in primary school from Yamanshi Nichinchi Shimbun Newspaper. 
quality control. We remark with interest that a teaching/learning idea first tried in the United States in the 1800s led to reform of Japan's teaching via lesson sharing; Deming's work led to Japan becoming a world-class manufacturer of automobiles; and each of these two "American exports" to Japan have now come back to the United States in a distinctly different form, and have been adopted.

Lesson Study has four common features, which can vary widely based on specific implementations:

- Collaborative planning-Teachers brainstorm ideas for a particular lesson, often focusing on particularly difficult teaching situations they have encountered, and then develop a preliminary lesson.

- Lesson observation by colleagues-One member of the group teaches the preliminary lesson, while the others observe both the teacher's delivery and the students' reception.

- Analytic reflection-Teachers engage in group-critique of the lesson, evaluating its strengths and weaknesses.

- Ongoing revision-The group moves back to solve problems iteratively until pleased with the end result, that is, the final version of the lesson (Fernandez, 2008).

From start to finish, this professional development process for each individual lesson requires at least three months and sometimes six months or longer. It is critical to say that while a very high-quality lesson is produced, the Lesson Study process is at heart a professional development tool.

Encouraged by success in Japan, US teachers in recent years have begun to engage actively in the practice. However, because of the diffuse educational "system" in the United States that varies widely between districts and even between schools in the same district, the extent of use of Lesson Study is difficult to quantify. Catherine Lewis has identified more than 3300 US teachers who have actively engaged in Lesson Study since 2006 (Mills College Lesson Study Group). Separately, CPALMS, the previously cited project of Florida State University, has supported thousands of teachers in the Lesson Study process with training, funding, and resources since launching its Lesson Study Initiative in 2009. Other organizations such as the Educational Testing Service (ETS) and the Greenwich Japanese School have also championed Lesson Study, training many hundreds of teachers each year (Arani, Shibata, \& Matoba, 2007). Combined, it is likely there are at least 10,000 teachers who have practiced or are practicing Lesson Study in the United States.

Lesson Study appears to be applied very differently across schools. Some schools develop incredibly detailed lesson plans while others only iterate through the process once, without much revision. At one school in Connecticut, the Lesson Study groups often go through one or more "mock teaching" sessions with other teachers, allowing teachers to revise the presentation and even the wording of specific parts of the lesson. Teachers even create diagrams to represent what will be presented on the blackboard and when each topic will be added. However, schools we have observed that use primarily lecture-style teaching found that the process was not particularly valuable simply because the observed benefits of the process did not compensate for the time invested by the Lesson Study team. Teachers developing lecture-style lessons typically iterated through the Lesson Study process only once before feeling that the lesson was high quality.

A teacher from a New York school told us that his school was moving from lecturing toward problem-based learning in an attempt to engage teachers more deeply in the Lesson Study process. For instance, during problem-based learning exercises, it is easy for students to experience wide swings in their level of engagement, from becoming lost in problems that are too challenging to being bored by problems that are too easy. Lesson Study teachers can overcome this challenge by developing "clue" cards they hand out to students who are particularly lost or frustrated by a difficult problem. This is especially ripe for Lesson Study, where finding "the right clue" that will make the solution attainable without making it too easy (and thus inauthentic) takes many iterations and testing.

Finally, many American teachers are excited to use Lesson Study to develop new lessons based on the Next Generation Science Standards (NGSS) and Common Core State Standards (CCSS) in Math and English. Many teachers feel that the new standards (and resulting curricula) are so complicated that it will take a Lesson Study group working cooperatively to pull apart the meaning behind each standard.

In an attempt to make the practice of Lesson Study more uniform across the United States, some have developed "resource kits" that walk teachers step-by-step through the development process. CPALMS has created a support system that coordinates all the communication and work done among Lesson Study teams so that team members can be dispersed across different schools. These resource kits also provide teachers with access to research articles and other tools to support their professional development. Early evidence suggests this is becoming a successful "Train the Trainers" program. 


\subsection{The Benefits of Lesson Study}

Lesson Study appears to offer many positives. It has made teachers more aware of and critical of day-to-day classroom activities. Through the Lesson Study iterative process, individual teachers take on the role of reflective professional researcher and can observe their own actions and the actions of others more objectively (Roberts, 2010). Because the group dynamic revolves around the practice of critical discussions, each teacher feels safe to criticize constructively the outcomes of the lesson to improve it. This leads to a spillover effect in which other teachers become more critical of their own lessons once they have become comfortable with the iterative process of improving their practice (Droese, 2010). This also encourages teachers to become more receptive to feedback on their lessons and teaching methods from educators outside the Lesson Study group. One teacher in Connecticut told us, "My group of teachers has been able to effectively create a safe space for each other to give feedback and criticize without being rude and especially without having high-stakes attached. This has helped all of us, new and experienced, grow as teachers."

As a result of these self-critical habits, Droese (2010) found increased collaboration across entire schools, and not just among those participating in Lesson Study groups, as the culture shifted to an environment of cooperation, collaboration, and self-reflection. But it remains a fact that few empirical studies have examined the detailed outcomes of the Lesson Study process in the United States.

Following in the spirit of Pestalozzi, constructivism is a view of learning based on the belief that knowledge is not simply "content" given by the teacher at the front of the room to students at their desks. "Rather, knowledge is constructed by learners through an active, mental process of development; learners are the builders and creators of meaning and knowledge" (Grey, 1997). Lesson Study offers a constructivist method of teacher professional development. Thus, the effectiveness of constructivist learning techniques is not limited to the in-class lessons offered to the students themselves (Grennon, 1999; Schwandt, 1994). While most PD programs "lecture at" teachers, Lesson Study teachers are immersed in study and refection on alternative pedagogical methods. This allows teachers to see strengths and weaknesses firsthand and construct their own understanding of how best to use these methods. Researchers have found these active participants are much more likely to adopt new pedagogical models (Roberts, 2010). Further studies also found an increase in teacher-created use of studentcentered learning techniques (Droese, 2010).

The situation is not all rosy. US educators implementing Lesson Study have encountered some barriers, the most significant being the time required to conduct such extensive professional development. As mentioned above, the teaching workload for US teachers is significantly higher than that of their Japanese counterparts. In the initial test cases of Lesson Study in the United States, teachers were not provided with "comp time" that perhaps might have involved using weekly substitute teachers. Instead, stressed and stretched participating teachers sought time for Lesson Study on top of their normal workloads, spending significant personal time conducting the sessions. Teachers became mentally and physically exhausted and wary of widespread adoption (Roberts, 2010).

Other studies related to STEM subjects have identified that science or math specialists who are not responsible for teaching regular classes are essential to implementation, because they can take on larger roles in the planning process and alleviate some of the time pressure on teachers. While such a method alleviates some time strain on teachers, it adds costs that many school districts simply cannot afford.

Too often, the breadth of content in the "American curriculum" exerts pressure for teachers to ignore in-depth lessons with their pedagogical sophistication and to focus instead on easier-to-teach lecture-style classes (Herman \& Golan, 1991). Correspondingly, the demand for sophisticated lessons that take three to six months to develop is often weak. For example, US 1st graders are taught 22 concepts in mathematics, on average, whereas the countries that perform best on international measures, including Japan, teach an average of five concepts in 1st grade mathematics (Schmidt, Houang, \& Cogan, 2002).

Compounding this effect, the use of standardized tests as part of an accountability system for teacher performance has the effect of forcing teachers to teach even more tightly to the test content (Herman \& Golan, 1991). While Japanese students must also take standardized tests, those tests do not have such a prominent place in the lesson development process. Less than $5 \%$ of Japanese teachers reported that standardized tests played a "major role" in their decisions on how to teach a particular content area, compared to $23 \%$ of US teachers (NCES, 2006). Under the current workload and curricula requirements, US teachers who want to pursue programs such as Lesson Study cannot do so without committing personal time or placing the cost of extra time onto other personnel assets (such as science and math specialists). 
Many US educators who advocate Lesson Study focus on the PD outcomes, not on the lessons themselves. These lessons are not shared in any systematic way. They are spread only through informal networks of teachers, or at most around their school districts of origin. Hundreds of person-hours may be devoted to developing a lesson that ends up on a shelf, used in perhaps only a few classrooms each year. This is also true in Japan, where thousands of high-quality lessons are developed across the country; there is no institutionalized sharing of lessons. With a national curriculum, any lesson developed by a group of teachers in a small rural town could be used by teachers across Japan, and yet these lesson plans are only shared, if at all, through informal networks within a school (Yoshida, 1999).

\section{Moving beyond a Craft Industry: The Co-Implementation of Lesson Study and Lesson-Sharing Services}

While both Lesson Study and lesson sharing hold promise, we propose that the merged adoption of Lesson Study with lesson sharing would be hugely synergistic. Implementation of one solves many problems in the implementation of the other. They are mutually supportive. However, it will take policy and system changes to take advantage of the high-quality lessons developed by Lesson Study and then shared by lesson-sharing services.

If Lesson Study is adopted at scale, thousands of high-quality lessons would be produced each year, in a loose sense, through vetted crowdsourcing. While these lessons may still have some unevenness of quality, the majority would be ready for sharing with little effort from teaching and content experts, solving the problem of uneven content creation encountered by many lesson-sharing services. Each of the vetted group-created lessons would be shared only after months of rigorous development by a team of teachers. They could be distinguished from the rest by some type of branding, analogous to CPALMS' equivalent "Good Housekeeping Seal of Approval."

With increased overall quality, and the guarantee that a team of teachers worked for months on each lesson, other teachers would not have to spend as much time sorting through the large number of lessons, saving search time and leading to wider adoption. After only a few minutes of searching, a well-prepared teacher would have identified an excellent lesson to use in her/his class.

Only experience will reveal how much additional time would be required by that teacher to master the lesson. Lesson Study lessons tend to be more complex, more sophisticated, and require study time not only for content but for pedagogy and understanding how to handle class questions or misperceptions, down to minute details. So, a teacher who has found the right lesson may require more than one evening of studying the lesson to present it to the class. Recall the difficulty of isolated US teachers in the 19th century trying to adopt Pestalozzi's teaching plans? Perhaps our 21st-century teacher can create a Lesson-Study local team of teachers, each finding great lessons on the Internet, and then discussing and presenting their outlines to the group, as a type of preparatory Lesson-Study-motivated PD, all prior to offering lessons to the class. Manor New Tech High School in Texas, while not practicing Lesson Study explicitly, regularly uses team teaching to develop interdisciplinary lessons. Rather than requiring teachers to take up time in their evenings to plan their joint lessons, they spend the entirety of each Monday morning co-developing lessons with other teachers while students are in a study hall session. This type of shared activity could accompany the Lesson-Study finding and delivery process.

In the long term, the coordinated implementation of Lesson Study and lesson sharing should lead teachers out from their isolated craft industry into a new era of technology-enabled teaching. Teachers would employ the body of high-quality lessons online through lesson-sharing services and use their newfound time to develop, with others, one or two high-quality lessons each year to add to this body of knowledge. This would move individual teachers up the value chain. Time spent on routine lesson planning would be replaced with helping specific students having difficulties and, occasionally, developing a lesson with others that will be used around the country. However, in the short term, it will take a focused set of substantial policy changes to move the system towards this more productive state.

\section{Institutional Support Required for Successful Implementation}

From a national policy perspective, a key issue is whether we expect individual teachers and individual schools to adopt Lesson Study and then post their refined lessons on the Internet, perhaps for free as open educational resources (OER) or perhaps for a fee, and whether we provide some federally funded program to kickstart the 
process. These are questions for national policy makers. Bottom-up, or aid from top down?

Whatever the answers, the timing is right to consider such support, as US STEM teachers are currently overwhelmed with CCSS and NGSS implementation. These new ways of teaching mathematics and science are very conducive to Lesson Study efforts, invoking Pestalozzi's ideas in active hands-on learning. For instance, the NGSS require students in the classroom to act and think like scientists, posing hypotheses, collecting data, offering mental and sometimes mathematical models of the problem, accepting failure when, as is inevitable, they go down a wrong path, and eventually tying their work to that of engineers who wish to apply science to the design and creation of useful and exciting new things. This is active learning in the sense of Pestalozzi.

The history of teaching in the United States reveals that a lack of attention to teacher training (focused PD) can spell doom for the implementation process. Teaching in support of CCS and NGSS is not scripted didactic lectures. For each new set of standards, the decision has been made to do less teaching that is a mile wide and an inch deep and cover selected material in much more depth, in active learning modes. To implement Lesson Study successfully in the United States, teachers must have time to meet and design their lessons. Those who download Lesson-Study lessons from the Internet must have some local supportive system that enables them effectively and efficiently to comprehend the subtleties of the lesson they have chosen. In this classic case of quantity versus quality, Deming would argue for quality.

We can only speculate about what would happen during the start of a merged or "married" system of Lesson Study and lesson sharing. During initial implementation, teachers may not have free time for Lesson Study, as many existing lesson-sharing services do not in fact offer net reduced time per lesson. As we have discussed, it is the search, vetting, and selection process that adds time. Lesson-sharing services will likely require a few years to accumulate a sufficient number of high-quality lessons developed by Lesson Study groups. During this transition period, school districts and schools would have to find ways to free up time in teachers' schedules to pursue Lesson Study. Paying for substitute teachers could accomplish this, but at significantly increased costs.

One solution would be to decrease the number of hours students are in class, thus decreasing the number of teaching hours. This time could be used for Lesson Study. While it would be controversial to take instruction time away from students every week for the purpose of teacher professional development, it may well be more valuable for students to have four hours each week of well-thought-out investigative learning than five hours of lecture-style lessons.

One teacher we have worked with in Massachusetts has seen that "teaching in-depth lessons is slow at the start. You fall behind other sections of the same class, but by the end of the semester, when content is more difficult, you can fly through content rapidly because students actually learned the concepts instead of memorizing the answers for a test."

If these "marriage-of-two-systems" ideas are to be implemented, perhaps with federal funding support, it may present an opportunity to tackle the issue of standardized testing, one of the persistent sticking points in US education policy. Opponents criticize standardized tests for forcing students to learn by rote and evaluating teachers and schools on such a flawed metric. Proponents acknowledge many of these shortcomings, but argue that standardized tests provide the fair evaluation system necessary for improving schools. Neither side had changed positions in the last decade, nor does any change seem likely in the next decade either.

There is a third path: Lesson Study groups can provide their own system of accountability, as is done informally in Japan (Stigler, 2010). There, Lesson Study is also used to co-develop common tests across classrooms that are then graded and analyzed together. Teachers whose students are chronically performing lower than those in other classrooms are given extra assistance to improve their teaching. Principals have access to this information and can watch as teachers improve (or do not improve) their teaching throughout the year, and make their recommendations at the end of the year. Lesson Study could also act as a system of ongoing feedback that both improves teaching and helps hold teachers accountable amongst their peers.

\section{Conclusion}

We can now enable Pestalozzi's dream of student-centered exploratory learning and, at the same time, support the new national standards in mathematics and science. Together, lesson study and lesson sharing via the Internet hold the potential for transforming professional development and pedagogical effectiveness in classrooms.

We described the benefits and limitations of lesson study and lesson sharing, including a discussion of the barriers to implementation in US schools. We also described the expected results of the co-implementation 
("marriage") of these two initiatives, based on the expectation that they complement each other well, with each initiative overcoming many of the other's implementation barriers.

A vital component of success moving forward is intense focus on teacher professional development. History has shown that lack of attention here almost guarantees failure. Even without our proposed marriage being consummated, NGSS and CCSS will require extensive teacher PD. The "going deep" knowledge and pedagogical requirements of NGSS and CCS imply major new commitments in professional development. Any STEM teacher who has only shallow content knowledge that is acceptable for scripted didactic lectures will not be equipped to teach to the new standards. So, our insistence of this new commitment to PD is independent of the marriage between lesson study and lesson sharing, but enactment of the commitment will enable a happier marriage.

To move forward, we must anticipate possible new barriers. We need to implement forward-looking support mechanisms that will encourage a new paradigm of group-created, shared lesson planning by teachers, stepping away one day at a time, but once and for all, from the burdensome and isolated craft industry of individual lesson planning. Deming would smile, as would Pestalozzi.

\section{Acknowledgements}

Fujitsu Laboratories of America supported research reported here, under a contract with the Massachusetts Institute of Technology (Towards Intelligent Societies: What Motivates Students to Study Science and Math? How Can We Provide Flexible Learning Pathways?). The findings and opinions presented herein are those of the four authors and do not necessarily represent the views of Fujitsu Laboratories of America or of the Massachusetts Institute of Technology. We thank Jacob Foster, Rabieh Razzouk, and Reen Gibb for their helpful reviews of earlier drafts of the manuscript.

\section{Notes}

[1] The term "lesson study" is a translation of the Japanese phrase jugyo kenkyuu; jugyo, means instruction, lesson, or lessons and kenkyuu, means research or study (http://www.plcwashington.org/domain/48). The term, coined by Makoto Yoshida, "can also be translated in reverse as 'research lesson' [coined by Catherine Lewis, 2002], which indicates the level of scrutiny applied to individual lessons." (RBS Currents, Spring/Summer 2002).

\section{References}

Arani, M. R. S., Fukaya, K., \& Lassegard, J. P. (2010). Lesson Study as Professional Culture in Japanese Schools: An Historical Perspective on Elementary Classroom Practices. Nichibunken Japan Review, 22, 171-200.

Arani, M. R. S., Shibata, Y., \& Matoba, M. (2007). Delivering Jugyou Kenkyuu for Reframing Schools as Learning Organizations: An Examination of the Process of Japanese School Change. Nagoya Journal of Education and Human Development, 3, 25-36.

BetterLesson.com. blog.betterlesson.com

Droese, S. (2010). Lesson Study in the US: Is It a Mechanism for Individual and Organizational Change? A Case Study of Three Schools. Ph.D. Dissertation, Madison: The University of Wisconsin.

EdSurge (2013). TeachersPayTeachers Gets New CEO. https://www.edsurge.com/n/2013-06-05-teacherspayteachers-gets-new-ceo

Fernandez, M. (2008). Developing Knowledge of Teaching Mathematics through Cooperation and Inquiry. Mathematics Teacher, 1, 534-538.

Grennon, J. B. (1999). In Search of Understanding: The Case for Constructivist Classrooms. ASCD.

Grey, A. (1997). Constructivist Teaching and Learning. Saskatchewan Schools Trustees Association Research Center. http://www.saskschoolboards.ca/old/ResearchAndDevelopment/ResearchReports/Instruction/97-07.htm - What is Constructivism?

Herman, J., \& Golan, S. (1991). Effects of Standardized Testing on Teachers and Learning—Another Look. Los Angeles, CA: National Center for Research on Evaluation, Standards and Student Testing, UCLA.

Ingersoll, R. M. (2001). Teacher Turnover and Teacher Shortages: An Organizational Analysis. American Educational Research Journal, 38, 499-534. http://dx.doi.org/10.3102/00028312038003499

Larson, R. C. (2009). Education: Our Most Important Service Sector. Service Science, 1, i-iii. 
http://dx.doi.org/10.1287/serv.1.4.i

Larson, R. C. (2011). Foreword. In H. Demirkan, J. C. Spohrer, \& V. Krishna (Eds.), Service Systems Implementations (p. v). New York, NY: Springer.

Lewis, C. (2002). Does Lesson Study Have a Future in the United States? Nagoya Journal of Education and Human Development, 1, 1-23.

Makinae, N. (2010). The Origin of Lesson Study in Japan. The 5th East Asia Regional Conference on Mathematics Education: In Search of Excellence in Mathematics Education, 15, Tokyo.

National Center for Educational Statistics (NCES) (2006). Teaching Science in Five Countries: Results from the TIMSS 1999 Video Study. US Department of Education.

OECD (2012). Education at a Glance 2012: OECD Indicators. OECD Publishing.

Pavey, S. (2012). Plan-Do-Check-Act (PCDA). Mindtools. http://www.mindtools.com/pages/article/newPPM_89.htm

Rillero, P. (1993). The Enlightenment Revolution: A Historical Study of Positive Change through Science Teacher Education. The Journal of Science Teacher Education, 4, 37-43. http://dx.doi.org/10.1007/BF02628884

Roberts, M. (2010). Lesson Study: Professional Development and Its Impact on Science Teacher Self-Efficacy. Ph.D. Dissertation, New York: Columbia University.

Schmidt, W., Houang, R., \& Cogan, L. (2002). A Coherent Curriculum: The Case for Mathematics.

Schwandt, T. A. (1994). Constructivist, Interpretivist Approaches to Human Inquiry. In N. K. Denzin, \& Y. S. Lincoln (Eds.), Handbook of Qualitative Research (pp. 118-138). Thousand Oaks, CA: Sage.

Stigler, J. (2010). Needed: Fresh Thinking on Teacher Accountability. Education Week, 29, 30-36.

TeachersPayTeachers (2014) http://www.teacherspayteachers.com/About-Us

Yamanshi Nichinchi Shimbun Newspaper (2012). Students in Lesson Study Classroom [Photograph].

Yoshida, M. (1999). Lesson Study [Jugyokenkyu] in Elementary School Mathematics in Japan: A Case Study. American Educational Research Association 1999 Annual Meeting, Montreal. 